\title{
INFESTATION LEVEL AND SPATIAL DISTRIBUTION OF PROTOANCYLODISCOIDES MANSOURENSIS EL-NAGGAR 1987, A MONOGENEAN GILL PARASITE FROM THE LONG FIN CATFISH CHR YSICHTHYS AURATUS GEOFFROY, 1809
}

\author{
Ahmed M. El-Naggar And Enayat S. Reda \\ Zoology Department. Faculty of Sciences, Mansoura Univ \\ Mansoura, Egypt
}

Key words: Chrysichthys atratus. Protoancylodiscoides mansourensis: Monogenea. infestation level. microhabitat distribution.

\begin{abstract}
$A$ total of 110 specimens of the Nile catfisin Chrysichihys currcuns: Awere caught from Damietta Branch of the River Nile during spring and summer 2002 and 2003 and surveyed for monogenean gill parasites. Only a single highly host specific monogenean. namely Protoancylodiscoides mansourensis El-Naggar, 1987 was encountered. Out of the fish examined. 2224 monogenean worms were recovered. The parasite showed an aggregated or contagious pattern of distribution within the host population. The parasite attained high prevalence $(97.27 \%)$. abundance $(20.22 \pm 21.74)$ and mean intensity $(20.79 \pm 22.03)$ values. The parasite preferred larger hosts than smaller ones. Spearman Correlation Coefficient showed a positive relationship between host length or weight and intensity of $P$. mansourensis. The skeletal support of the holobranch is provided with a powerful sieve or a complex trapping system. being formed of interlocking epidermal semi circular folds alternated with fold-free interspaces. Several gill filaments were branched once. twice and even three times to produce additional filaments, probably to increase the gas exchange capacity in the oxygen-poor bottom of the river bed. The present model showed marked microhabitat availability as hundreds of thousands of attachment sites (each comprising two adjacent gill lamellae and an interlamellar channel) accessible for monogenean infestation were calculated on the host gills. The distribution of the parasite on the gills was non-random. The parasite showed a gradual decline in the percentage distribution from the first (outermost) to the fourth (innermost) gill arch (holobranch) as well as
\end{abstract}


from the dorsal to the ventral gill segments. The parasite preferred the proximal half of the gill filaments over the distal. However, there was no significant difference in the percentage distribution of $P$. mansourensis between the left and right hand gill sets or between the anterior and posterior hemibranchs. Factors contributing to the microhabitat preference of the parasite on the gill map and those regulating its population growth among host individuals of different length or weight classes are discussed in detail.

\section{INTRODUCTION}

The continuous flow of oxygen-rich water currents over the gill sieve is maintained for powerful and predominant gas exchange attitudes (Hughes, 1984). Hughes \& Morgan (1973) and Ojha \& Hughes (2001) showed that water currents immersing the gills may also carry ectoparasites and other pollutants such as heavy metals and insecticides to the gill tissue where they bring them in close proximity to the gill epithelium. Thereby, these organisms become attached to, or penetrate the gill tissue and obtain adequate nourishment. reproduce and flourish to build up regular populations. Gill inhabitants comprise a variety of parasite taxa, for example protozoans, monogeneans, digenean metacercariae, crustacean copepods and molluscs. Monogeneans are highly host and site specific parasites (Llewellyn, 1956: Suydam, 1971; Haneck and Fernando, 1978; Koskivaara et al., 1992; Rohde, 1993; Gutierrez and Martorelli, 1994 \& 1999; Lyndon and Vidal-Martinez. 1994; ElHafidi et al., 1998; El-Naggar et al.. 2001. El-Naggar \& El-Tantawy, 2001). Such brand of parasites are successful inluabitants of the external surfaces of the host fish where they invade a relatively broad spectrum of microhabitats, namely gill lamellae. gill filaments. skeletal support of the gill arch (holobranch). gill rakers. fins. nasal fossae, skin surfaces. buccal cavity and anterior sector of the oesophagus (El-Naggar et al., 2001). Differences of the microhabitat preference by gill monogeneans have been attributed either to differences in the magnitude of water current flowing over the gills or to variation in the surface area among different gill microhabitats. Chalupsky and Leps (1985) hypothesized that the spatial pattern of a living organism is caused by cerlain processes in the population or community and/or influence of environment. Several studies have revealed that niche restriction among monogeneans is a reflection of biotic interactions such as competitive coexistence (El-Naggar and 
El-Tantawy, 2001), competitive exclusion. (Paperna, 1964, and Buchmann, 1988) or co-occurrence (Dzika and Szymanski. 1989).

Host size (length or weight) has been documented by many authors to be one of the most important biotic factors that determine the infestation level of monogenean parasites (Buchmann. 1989; Hayward et al.. 1998: Hagras et al., 2001). Host length was reported by many authors to exhibit either a positive (Buchmann. 1989; Lo et al.. 1998; and Zelmer and Arai. 1998) or negative (Shotter. 1973: Khidr, 1990) relationship with the prevalence and/or intensity of fish parasites. Haas (1994) assumed that parasites that locate fish hosts through chemotaxis or phototaxis should have an infrapopulation size that is dependent on host size as larger hosts make better targets. Zelmer and Arai (1998) suggested that parasite infrapopulations that increase as the result of simple accumulation is expected to do so as a result of increasing host age. Such parasites should have either a direct life cycle or utilize an intermediate host whose ingestion is not limited by fish size and should, therefore, be present in most host size and age classes. However, Hagras et al. (1995 \& 2001) found that medium-sized host individuals accommodate higher numbers of monogenean worms than smaller and larger host individuals. The authors attributed this distribution pattern to the fact that mediumsized host individuals are the most active where they exhibit the highest breathing rates. leading to greater volumes of ventilation currents flowing over their gills and subsequently increased opportunities for oncomiracidium/gill microhabitat contact.

To the best of our knowledge. no previous studies were made of the ecological aspects of the ancyrocephaline monogenean Proloancylodiscoides mansourensis from the gills of the Egyptian long fin catfish Chrysichthys auratus. Only a taxonomical report has been given by El-Naggar (1987), however there is a paucity of information regarding the ecological aspects of $P$. mansonrensis. The present study aimed to report on the occurrence and spatial distribution of $P$. mansourensis El-Naggar, 1987 infesting feral (natural) populations of $C$. auratus Geoffroy, 1809 inhabiting Damietta Branch of the River Nile at Mansoura. The present study aimed also to report on available gill microhabitats. to describe the morphology of the gills of $C$. auratus and to demonstrate the relationship between host size (length and weight) and intensity of $P$. mansourensis. 


\section{MATERIALS AND METHODS}

Specimens of the bottom dweller catfish Chrysichthys auratus were caught with special nets from Damietta Branch of the River Nile during spring and summer in 2002 and 2003. According to Bishai and Khalil (1997), synonyms of Chrysichthys auratus are Pimelodus auratus, Porcus auratus, Bagrus auratus and Chrysichthys macrops. Fish were immediately fixed in $10 \%$ formaldehyde and transported to the laboratory in appropriate container. Prior to dissection of the gills. the total length (measured in centimeters from the tip of the snout to the posterior edge of the caudal fin) and weight (measured in grams) of each studied fish individual were recorded. The total length of collected host specimens ranged between 11.1 and $20 \mathrm{~cm}$. Host length range was divided into three approximately equal intervals. namely class I (from 11.1 to $14 \mathrm{~cm}$ ), class II (from 14.1 to $17 \mathrm{~cm}$ ) and class III (from 17.1 to $20 \mathrm{~cm}$ ). The total weight of collected host specimens ranged between 10 and $102 \mathrm{gm}$. Host weight range was divided into three approximately equal intervals, namely class I (from 10 to 40 $\mathrm{gm}$ ), class II (from 41 to $71 \mathrm{gm}$ ) and class 111 (from 72 to $102 \mathrm{gm}$ ).

To describe the availability of gill microhabitats of C. anratus. gill filaments of each holobranch were counted on 5 candidates of each length class. Thereafter, the gill lamellae and interlamellar channels on each gill filament were estimated. The total length of a given gill filament was measured and the mean number of gill lamellae per one millimeter was calculated. To study the morphology' of surface epithelium of the gills, specimens were prepared for scanning electron microscopy according to El-Naggar and ElTantawy (2001).

To demonstrate the spatial distribution of $P$. mansonrensis on the gills of $C$. auratus. an arbitrary division of the gills was designed. The gills were divided into left and right hand gill sets (lateral partitioning), with respect to the body of the fish. Each gill set was divided into four gill arches (holobranchs) numbered I-IV in an anteroposterior succession from the first (outermost. close to the operculum) to the fourth (innermost, close to the medial axis of the body) (transverse partitioning). Each holobranch was divided into anterior and posterior hemibranchs and each hemibranch was divided into three approximately equal segments, namely dorsal, middle and ventral (longitudinal partitioning). The gill filaments of each hemibranch were divided equally into proximal half (close to the skeletal support of the holobranch) and distal (in the vicinity of the 
floor of the buccal cavity). Monogenean worms were localized on the gill map, counted under a stereomicroscope and identified with the aid of high power light microscope.

The ecological terms prevalence. intensity and mean intensity were used as defined by Bush et al. (1997). The prevalence means the percentage of infestation and is calculated by dividing the number of infested by the number of examined host individuals and the output datum is then multiplied by 100 . The intensity means the number of parasites encountered on the gills of a fish. The mean intensity is defined as the mean number of worms per an infested fish. The abundance is defined as the mean number of worms per examined fish ( infested and non infested) Statistical analysis was performed according to El-Naggar and El-Tantawy (2001). One-way ANOVA test accompanied with Duncan's multiple range test (SPSS package. version 6) was employed to test for difference in the number of monogenean worms among available microhabitats as well as among different length or weight classes of the host. Moreover. Spearman Correlation Coefficient was selected on the same statistical package to clarify the nature of the relationship between the intensity of $P$. mansourensis and host length or host weight.

\section{RESULTS}

\section{General report on the infestation level $P$. mansourensis:}

Out of 110 fish examined, a total of 2224 individuals of the oviparous monogenean Proloancylodiscoides mansourensis were counted on the gills of the long fin catfish Chrysichthys culrutus. The prevalence, abundance and mean intensity values of the parasite were $97.27 \% .20 .22 \pm 21.74$ and $20.79 \pm 22.03$ respectively. There was a marked heterogeneity with respect to the infestation level among host individuals. Few host individuals harboured considerable numbers of monogenean worms whereas the vast majority of individuals accommodated comparatively fewer numbers. Only three individuals of the catfish were not infested. Out of 2224 monogenean worms encountered, 149 worms were recorded on the gills of one specimen of the catfish. Moreover, 96 worms were collected from the gills of another specimen of the catfish. Few host individuals accommodated between 50 and 70 Protoancylodiscoides worms. Similarly, few host individuals harboured between 20 and 50 worms. Other host individuals showed low infestation level that ranged between 1 and 25 monogenean worms/fish. 


\section{Distribution of $P$. mansourensis among size classes of the host :}

Figures 1 and 2 illustrate the prevalence and intensity values of $P$. mansourensis on different length and weight classes of $C$. ciuralus. The parasite attained a non-random distribution among different length classes. The prevalence value increases gradually from the fish length class I $(11.1-14 \mathrm{~cm})$ to the fish length class III $(17.1-20 \mathrm{~cm})$ (Fig. 1). The parasite attained its maximum prevalence (100\%) and mean intensity $(41.65 \pm 34.85$ worms/fish) on fishes belonging to length class III, however it attained its minimum prevalence $(91.67 \%)$ and mean intensity ( $9.27 \pm 11.42$ worms/fish) on fishes belonging to length class I (Figs. 1 and 2). The parasite recorded a prevalence of $98.49 \%$ and mean intensity of $18.26 \pm 13.95$ worms/fish on fishes of the length class II.

One-way ANOVA test indicated that difference in the intensity values among the three length classes of $C$. auratus were very highly significant (F-ratio $=17.6989$, F-probability $<0.001$ ). Further statistical analysis (Duncan's multiple range test) indicated significant difference in the intensity values of $P$. mansourensis between length class III and each of the other length classes (I and II) as well as between length classes II and I. Spearman Correlation Coefficient showed a highly significant positive relationship between host length and intensity of $P$. mansourensis $\left(\mathrm{r}^{2}=0.53, \mathrm{p}<0.001\right)$.

Similar non-random distribution was recorded for $P$. mansourensis among different weight classes of the host fish. The prevalence value increases gradually from the fish weight class I (10$40 \mathrm{gm}$ ) to the fish weight class III (72 -102 gm) (Fig. 1). The parasite attained its maximum prevalence $(100 \%)$ and mean intensity $(47.87 \pm 36.95$ worms/fish) on fishes belonging to weight class III, however it attained its minimum prevalence (94.74\%) and mean intensity (10.78 11.72 worms/fish) on fishes belonging to weight class I (Figs. 1 and 2). The parasite recorded a prevalence of $98.25 \%$ and mean intensity of $19.96 \pm 14.67$ worms/fish on fishes of the weight class Il.

One-way ANOVA test indicated that difference in the intensity values among the three weight classes of $C$. curratus were very highly significant $(F-$ ratio $=22.5747$, F-probability $<0.001)$. Duncan's multiple range test indicated significant difference in the intensity values of $P$. mansourensis between weight class III and each of the other weight classes (I and II) as well as between weight classes II and 1. Spearman Correlation Coefficient showed a highly significant 
positive relationship between host weight and intensity of $P$. mansourensis $\left(\mathrm{r}^{2}=0.52, \mathrm{p}<0.001\right)$.

\section{Availability and morphology of the gill microhabitats:}

Similar to the vast majority of freshwater teleosts, the gills of C. auratus comprise four pairs of bright red gill arches (holobranchs). numbers I-IV from the cranial to caudal position. Each gill arch consists of two hemibranchs which extend posterolaterally from the skeletal support of the holobranch. The first. second. third and fourth holobranchs (anterior and posterior hemibranchs combined) of fishes measuring 11.1-14 cm accommodated 106, 106, 116 and 86 gill filaments respectively. The holobranchs of fishes measuring 14.1-17 $\mathrm{cm}$ harboured 122,122, 136 and 110 gill filaments respectively. However, the holobranchs of fishes measuring $17.1-20 \mathrm{~cm}$ possessed $136,136,140$ and 116 gill filaments respectively. Concerning fishes of length class 1 . the total length of the gill filaments on the holobranchs was 212.170 .135 and $86 \mathrm{~cm}$ respectively. Regarding fishes of length class II. the total length of the gill filaments on the holobranchs was $328,281,236$ and $202 \mathrm{~cm}$ respectively. Concerning fishes of length class III. the total length of the gill filaments on the holobranchs was 657.657 .457 and $348 \mathrm{~cm}$ respectively. The mean number of gill lamellae/one millimeter gill filament was 33.76 lamellae. Each monogenean worm of $P$. mansourensis secures itself between two adjacent gill lamellae.

The skeletal support is provided with a powerful sieve formed of a complex trapping system. The later comprises a variable number of semicircular folds located on the dorsal and lateral surfaces. The folds project over the surface of the skeletal support and unite together to form barriers separated by fold-free interspaces. Moreover, folds were extended to cover the basal. one-fifth of the gill filaments. Stereomicroscope observations indicated that the folds of a given holobranch interlock with fold-free interspaces of the adjacent holobranch and vice versa to create a complex trapping system. Stereomicroscope observations showed also that several gill filaments on each holobranch undergo gross proliferation. Frequently, the gill filament was branched once, twice and even three times to produce additional filaments showing typical features of the original gill filaments. Such branching commenced at the middle third of the gill filament. 
Scanning electron microscope observations revealed that each gill filament accommodates two rows of equally spaced gill lamellae (Fig. 3). Each gill lamella is semi-circular in shape and extends between the afferent and efferent borders of the filament (Fig. 3). The covering epithelium of the gill filament shows a more complex pattern. The epithelial cells are more irregular in shape and there is high frequency of pores from chloride and mucus-producing cells (Figs. 4, 5 and 6). They are decorated by a pattern of microridges which are either whorled (Fig. 5) or random (Fig. 6). The filamental surface comprises dominant pavement cells that are separated by adhesion zones (Figs. 4 and 5). Among the pavement cells. there are openings of mucous or mucus-producing cells (Figs. 4 and 6). Moreover, surface chloride cells varied in shape and size and were interposed between adjacent pavement cells (Figs. 5 and 6). The parasite showed a marked preference for the interlamellar channels or spaces to secure its haptor between two adjacent gill lamellae (Figs. 7 and 8).

\section{Some important features of the tegument of $P$. mansourensis :}

Scanning electron microscope observations showed that the tegument of $P$. mansourensis accommodate numerous pores and sensory receptors that are distributed over the dorsal and ventral surface of the parasite (Fig. 9). More details on the surface topography of $P$. mansourensis have been given by El-Tantawy (in print).

\section{Spatial distribution of $P$. mansourensis on the host gills :}

Figure 10 illustrates the microhabitat distribution of the oviparous monogenean Protoancylodiscoides mansourensis on the gill map of $C$. churctus. The parasite attained a non-random distribution among the four gill arches (holobranchs). among the dorsal, middle and ventral segments and between the proximal and distal halves of the gill filaments. Concerning their distribution over the four holobranchs. individuals of $P$. mansonrensis showed a gradual decline in their percentage distribution from the first (outermost) to the fourth (innermost) holobranch. One-way ANOVA test indicated that such microhabitat preference was very highly significant $(F$-ratio $=12.3462, F$-probability $<0.001)$. Further statistical analysis (Duncan's multiple range test) indicated significant preference for the first holobranch over the third and fourth ones. Similar significant preference was recorded for the second holobranch 
over the third and fourth ones. However. Duncan's multiple range test revealed that there was non significant difference in the number of monogenean worms between the first and second holobranchs. The maximum numbers of Protoancylodiscoides worms encountered on the holobranchs were 43,42,39 and 25 respectively.

Regarding their distribution over the gill segments. individuals of $P$. mansourensis showed a gradual decline in their percentage distribution from the dorsal segment to the ventral one (Fig. 10), with the dorsal gill segment being the most favourable attachment site for parasites. One-way ANOVA test indicated that such microhabitat preference was very highly significant $(F-r a t i o=22.1712 . \mathrm{F}$ probability $<0.001)$. Duncan's multiple range test indicated significant preference of $P$. mansolre'snis for the dorsal segment over the middle and ventral ones. Similarly. there was a signilicant preference of the parasite for the middle segment over the ventral. The maximum numbers of Proloancylodiscoides worms encountered on the dorsal, middle and ventral segments were 68.57 and 30 respectively.

Concerning their distribution over the proximal and distal halves of the gill filaments, individuals of $P$. mansourensis showed a marked preference for the proximal half than the distal one (Fig. 10). One-way ANOVA test indicated that such microhabitat preference was very highly significant $(F$-ratio $=47.7042, F$-probability $<0.001$ ).

The parasite showed a random distribution between the anterior and posterior hemibranchs as well as between the left and right hand gill sets (Fig. 10). The parasite attained slight preference for the anterior $(51.66 \%)$ over the posterior hemibranch (48.34\%) and for the left hand gill set $(52.97 \%)$ over the right one $(44.03 \%)$. Statistically. such microhabitat preference was non-significant concerning the anterior and posterior hemibranchs (One-way ANOVA: F-ratio= 0.1953 . F-probability $>0.05$ ) or the left and right hand gill sets (Oneway ANOVA: F-ratio $=0.6903$, F-probability $>0.05$ ).

\section{DISCUSSION}

The present investigation revealed that $P$. mansourensis attained markedly high percentage of infestation (97.27\%) within the host population. Moreover, $P$. mansourensis was found to be the single gill monogenean parasite of $C$. auratzis. Moreover, the parasite showed an aggregated or contagious distribution among host 
individuals, recording high intensity on few host individuals and low intensity on other host individuals. The parasite attained a mean intensity value of $20.79 \pm 22.03$ worms/infested fish. Bishai and Khali (1997) reported that $C$. curatus is a social benthic organisms with a restricted habitat in close proximity to the uppermost layer of the bottom sediment. The organism feeds upon aquatic insects, crustaceans and bottom deposits (Bishai and Khalil, 1997). Aggregation of host individuals in a definite sector of the water body seems likely to stimulate egg deposition by $P$. mansonrensis or facilitate the host finding by oncomiracidia that prevail in the vicinity of the social host fish. These processes could be initiated by chemical cues or physical communication among aggregated or shoaled host individuals. Chemicals elaborated by the host fish seems likely to be received by sensory receptors of the tegument of the parasite (see Lyons, 1969; El-Naggar, 1992; Yang and Lang, 1995). On the other hand, physical communication among members of the shoal appears to concentrate such chemical cues within a limited sector of the water column or alternatively stimulate the rheorecptors of the tegument. The present findings and those of El-Tantawy (in print) showed that the tegument of $P$. mansourensis acconmodates numerous sensory receptors that seem to support the sensory capabilities of the parasite with respect to the environmental signals.

Stereomicroscope observations revealed that the skeletal support of the holobranch of $C$. anratus is provided with a powerful sieve or complex trapping system comprising a variable number of semicircular folds and fold-free interspaces. Water currents immersing the gills first flows over the trapping system and then diffuse to pass over the gill lamellae and interlamellar channels before leaving the buccal cavity through the opercular opening. The powerful sieve may reduce the rate of arrival of invading oncomiracidia of $P$. mansourensis on the gill microhabitats. However. trapped oncomiracidia may attach to the surface of the skeletal support and later migrate through the slits of the sieve to contact an accessible gill microhabitat. Such adaptations may account for the considerable intensity values recorded for $P$. mansourensis in the present survey.

High host specificity of $P$. mansourensis to the long fin catfish seems likely to be shaped during the course of parasite evolution through a number of convergent phenomena starting with habits (microhabitat specialization and feeding styles) of free-living progenitors and the way in which the parasitic association arises 
(passive or active oral contamination) (see Sukhdeo and Sukhdeo, 1994). Adamson and Caira (1994) showed that the degree of host specificity a parasite species exhibits is the result of interplay of factors that act on various temporal scales. Many morphophysiological characteristics are best viewed as adaptations subsequent to, rather than determinants of, specialization (Adamson and Caira, 1994). Moreover. ethological aspects of infective stages of parasites such as miracidium and cercaria of Digenea and oncomiracidium of Monogenea can strongly influence the type of host infected (see Poulin ot al.. 1990; Haas. 1992). Sukhdeo and Sukhdeo (1994) hypothesized that optimal habitat selection by helminthes within the host environment is a reflection of proximate mechanisms of parasite habitat selection and ultimate selective. pressures.

Evolutionary ecology offers two major classes of explanation for habitat restriction (host specificity): limited dispersal and limited adaptations (Proctor, 1999). Some parasite species may have a narrow or limited host range simply because they do not come in contact with other sympatric hosts. The longfin catfish is a bottom dweller where its ecological and ethological constraints are restricted to a limited sector of the water column and this appears to create an ecological isolation for both the fish and its parasite load. However, hatched larvae (oncomiracidia) of $P$. mansourensis may swim actively or carried passively by the water current immersing the gills of cohabitant host species. Such intruders might have been incapable of successful establishment and/or reproduction on the microhabitats of the strange or non target host species. Transplantation of $l^{\prime}$ mansourensis among several sympatric host species could lead to an unavoidable extinction. However, it remains questionable that why. when and where $P$. mansourensis was stuck to the longfin catfish during the course of evolution of both?

Spearman Correlation Coefficient revealed a highly significant positive correlation between host length or host weight and intensity of $P$. mansourensis. Similarly, the parasite attained its maximum prevalence on large-sized fish and minimum value on small-sized ones. The increase of the infestation level (prevalence and/or intensity) with the increase in fish length or weight has been. attributed by many authors to the long term exposure of older and perhaps longer fish hosts to parasites or their more gregarious or sluggish habits that facilitate the transfer of parasites among host 
individuals (Khidr, 1990). The increase in the surface area of the gills of older and perhaps longer fish hosts (Cone and Burt, 1984) could be also an attribution. Khidr (1990) hypothesized that Oreochromis niloticus niloticus and Tilapia zillii accumulate more and more parasites as they get older. Similar increase of the infestation level with an increase in fish length was reported by Srivastava and James (1967) in Gyrodactylus inedius from Onosmustelus species and by Buchmann (1989) in Pseudodactylogyrus anguillate and P. bini from Anguilla anguilla.

Hagras et al. (1995, 2001) found that medium-sized fish harboured more monogenean worms than small-sized and larger ones. The authors attributed such infestation pattern to the fact that medium-sized fish are the most active forms and exhibit the highest breathing rates. Therefore, a greater volume of water currents is expected to immerse their gills and this in turn creates an increased opportunity of gill microhabitat/oncomiracidium contact. Hayward ef al. (1998) found that the intensities of Kuhnia sprostonue and Kuhnia scombri, the two most abundant parasites of Scomber scomberus and Pseudokuhnia minor and Kuhnia scombri, the most dominant parasites of Scomber australasicus, peaked in fishes $20-25 \mathrm{~cm}$ long. then decrease in larger fishes. The authors attributed their findings to the fact that larger scombrids become less susceptible to infection. or because fishes over $25 \mathrm{~cm}$ long develop immunity to the most dominant parasites. Alternatively, larger scombrids may simply school in habitats that are less frequently exposed to infective stages of parasites.

The present study revealed that the distribution of the monogenean $P$. mansontrensis on the gills of the catfish ( $C$. cumranus was non-random. The parasite attained highly significant preference for particular microhabitats than others. For example. the percentage distribution of the parasite gradually declined from the first to the fourth gill arch (holobranch) as well as from the dorsal to ventral gill segment. Similarly, the parasite attained very highly significant preference for the proximal half of the gill filament over the distal half. However, there was non significant difference in the number of Protoancylodiscoides worms between the anterior and posterior hemibranchs or between the left and right hand gill sets.

Kearn (1998) observed that distal parts of the gill filaments on neighbouring holobranchs are in regular contact and these parasites may migrate easily from one holobranch to the adjacent. Rohde (1980) and Lo and Morand (2000) hypothesized that the number of 
gill filaments and the surface area of holobranchs are correlated positively to the number of monogenean worm encountered on the gill microhabitats. The present study revealed that there is a gradual decline in the number of gill filaments. gill lamellae and available microhabitats from the first to the fourth holobranchs. Such gradient in microhabitat availability may account for gradual decline in the percentage distribution of $P$. mansourensis among gill holobranchs of C: cauratus.

Distal halves of the gill filaments are located towards the floor of the buccal cavity and are known to be the most exposed to the respiratory currents (Hughes, 1966). However, Lo and Morand (2000) argued that once settled, monogeneans appear to challenge the hydrodynamic forces. According to the present findings, $P$. mansourensis significantly preferred the proximal half of the gill filaments over the distal. Such microhabitat preference could be a reasonable adaptation to avoid (or neutralize) the risk of being swept off within the flowing water current that attains its highest magnitude over liss sheltered microhabitats such as the distal region on the gill filament. Moreover, folds on the skeletal support were found to extend over the basal sector of the filaments and this may prove an additional shelter for the parasites.

Differences between the left and right hand gill sets have been reported by Wootten (1974) in Dactylogyrus amphibothrizm from the gills of Gymnocephalus cernuc and by Lo and Morand (2000) in Haliotrema spp. from the gills Stegastes nigricans. In contrast. many authors found no significant difference in the distribution of monogenean worms (for example. Gutierrez and Martorelli, 1994; Buchmann. 1989; El-Naggar ef al., 2000). Moreover, anterior and posterior hemibranchs have been reported by many authors to harbour similar parasite burdens (see El-Naggar et al., 1997; El-Naggar and El-Tantawy, 2001). It seems likely that the left and right hand gill sets as well as the anterior and posterior hemibranchs accommodate the same number of microhabitats and show no marked heterogeneity with respect to morphometric features and magnitude and direction of the hydrodynamic forces acting on the gills.

Variability in microhabitat distribution among different gill monogenean species may be a reflection of differences in morphology and morphometry of the gills, hydrodynamic forces (direction and strength of water current) and/or behavioural aspects among various host species. It may be also attributed to intraspecific 
or interspecific biotic relationships (competitive exclusion, competitive coexistence, co-occurrence and resource-partitioning or predation) or may be a reflection of physical (temperature, oxygen saturation, water transparency, etc.) and/or chemical (salinity, alkalinity, $\mathrm{pH}$, etc.) environmental parameters. EL-Hafidi et al. (1998) assumed that the heterogeneity in the gill apparatus, physiology of the host, and structure of the larval and adult haptors may explain the spatial distribution of the monogeneans Metamicrocotyla cephalus and Microcotyle mugilis on the gills of the striped mullet Mugil cephalus. Rohde (1977) hypothesized that the segregation of adults in a small number of sites may favor chances of mating among cross-fertilizers.

Scanning electron microscope observations slowed that the tegument of $P$. mansourensis accommodates numerous pores that are distributed in a definite pattern on the surface of tegument (see ElTantawy, in print). Moreover, the tegument was observed to bear numerous single sensory receptors (cilia) and sensory papillae. Tegumental pores are probably respiratory channels required to aerate the underlying tissues of parasite that inhabits the gills of the bottom dweller catfish $C$. auratus. Sensory papillae and cilia are probably connecting units that communicate the internal body organs with the abiotic and biotic elements in the macroenvironment (environment of the host-parasite system) and microenvironment (environment of the parasite). Such adaptations appear to support the parasite skills required for optimizing its population growth and dispersal.

\section{REFERENCES}

Adamson, M. L. and Caira, J. N. (1994), Evolutionary Factors Influencing The Nature of Parasite Specificity. Parasitology. 109: S85-S95.

Bishai, H. M. and Khalil. M. T. (1997). Freshwater Fishes Of Egy'pt. Publication of The National Biodiversity Unit No. 9, Department of Natural Protectorate, Egyptian Environmental Affairs Agency.

Buchmann, K. (1988). Interactions Between The Gill-Parasitic Monogeneans Psudodactylogyrus Anguillac And P. Bini And The Fish Host Anguilla Anguilla. Bull. Eur. Assoc. Fish. Pathol., 8: 98-100. 
Buchmann, K. (1989). Microhabitats Of Monogenean Gill Parasites On European Eel (Anguilla Anguilla). Folia Parasitol.. 36: 21-329.

Bush, A. O. ; Laferty, K. D. ; Lotz, J. M. and Shostak, A. W. (1997). Parasitology Meets Ecology On Its Own Terms: Margolis Et Al. Revisited. J. Parasitol., 83: 575-583.

Chalupsky, J. and Leps, I. (1985). The Spatial Pattern Of Enchytraeidae (Oligochaeta). Oecologia (Berlin) 6s: 153158.

Cone, D. K. and Burt. M. D. B. (1984). Population Biology of Urocleidus Adspectus Muller, 1936 (Monogenea) On Perca Flavescens In New Brunswich. Can. J. Zool., 36: 272-277.

Dzika, E. and Szymanski, S. (1989). Co-Occurrence and Distribution Of Monogenea Of The Genus Dactylogums On The Gills Of The Bream, Abramis Brama L. Acta Parasitol. Pol., 3t: $1-14$.

El-Hafidi, F. : Berrada-Rkhami, O. ; Benazzou, T. And Gabrison, C. (1998). Microhabitat Distribution And Coexistence of Microcotylidae (Monogenea) On The Gills Of The Stripped Mullet Mugil Cephalus: Chance Or Competition? Parasitol. Res., 84: 315-320.

El-Naggar, A. A. and El-Tantawy, S. A. (2001). Competitive Coexistence And Microhabitat Specialization of The Monogenean Gill Parasites Pseudodactylogy'ts: Anguillice. P. Bini And Gyrodactylus Anguillae On The Immigrant European Eel. Anguilla Anguilla In Egypt. l. Union Arab Biol.. 16(A) Zoology: 137-160.

El-Naggar, M. M. (1987). Protoancylodiscoides Mansourensis N. Sp. A Monogenean Gill Parasite or The Egyptian Freshwater Fish Chrysichthys Auratus Geoffroy 1809. Arab Gulf J. > Scient. Res. Agric. Biol. Sci. B5 (3): 441-454. 
El-Naggar, M. M. (1992). Scanning Electron Microscope Studies On The Head Lobes And Haptor Of The Monogenean Gyrodactylus Groschafiti Ergens, 1973. J. Egypt. Ger. Soc. Zool., 8 (B): 435-445.

Ei-Naggar. M. M. : Hagras, A. E. : Mansour. M. F. and El-Naggar. A. M. (1997). Microhabitat Distribution And Coexistence of The Monogenean Gill Parasites of The Nile Cattish Clarias Lazera. J. Environ. Sci., 13: 227-243.

El-Naggar, M. M. ; Hagras, A. E. : Ogawa. K. : Hussien. A. B. and El-Naggar. A. M. (2000). Microhabitat Distribution And Coexistence of The Monogenean. Gill Parasites of The Cichlid Host Fishes Oreochromis Niloriciss And Tilapia Zilli. J. Union Arab Biol. 14 (A) Zoology: 455-470.

El-Naggar, M. M. ; El-Naggar, A. M. and El-Abbassy, S. A. (2001). Microhabitat And Movement of The Viviparous Monogeneans Gyrodactylus Alberti, Macrogyrodactylus Clarii And $M$. Congolensis From The Nile Catfish Clarias Gariepinus. J. Egypt. Ger. Soc. Zool.. 35(D): 169-187.

El-Tantawy, S. A. (2003). Scanning Electron Microscopy of The Tegument Of Prolouncylodiscoides Munsourensis. ElNaggar 1987. A Monogenean Gill Parasite From The Catfish Chrysichthys Auratus. J. Egypt. Ger. Soc. Zool. (In Print).

Gutierrez, P. A. and Martorelli, S. R: (1994). Seasonality. Distribution. And Preference Sites of Demidospermus: Valenciennesi Gutierrez Et Suriano, 1992 (Monogenea: Ancyrocephalinae) In Catfish. Res. Rev. Parasitol.. 5t (4):259-261.

Gutierrez, P. A. and Martorelli. S. R. (1999). Hemibranch Preference By Freshwater Monogeneans A Function Of Gill Area. Water Current, Or Both? Folia Parasitol., 46: 263-266.

Haas, W. (1992). Physiological Analysis Of Cercarial Behaviour. 3. Parasitol. 78: 243-255. 
Haas, W. (1994). Physiological Analysis Of Host-Finding Behaviour In Trematode Cercariae: Adaptations For Transmission. Parasitology, 109: S15-S25.

Hagras, A. E. ; El-Naggar, M. M. ; Mansour, M. F. and El-Naggar, A. M. (1995). Influence Of Age, Length And Sex of The Catfish Clarias Lazera On Infestation With Six Monogenean Parasites. Bull. Fac. Sci. Manoura Unjv.. 22 (2): 37-56.

Hagras, A. E. ; El-Naggar, M. M. ; Ogawa. K. : Hussien. A. B. and El-Naggar, A. M. (2001). The Relationship Of Host Sex And Length With The Infestation Level of Nine Monogenean Species On Two Cichlid Fishes From The River Nile And Manzala Lake, Egypt. J. Egypt. Ger. Soc. Zool., 35(D): 109-127.

Haneck, G. and Fernando, C. H. (1978). Spatial Distribution Of Gill Parasites Of Lepomis Gibbosus (L.) And Ambloplites Rupestris (Raf.). Can. J. Zool., 56: 1235-1240.

Hayward, C. J. ; Perera, K. M. L. and Rohde, K. (1998). Assemblages Of Ectoparasites Or A Pelagic Fish. Slimy Mackerel (Scomber Australasicus) From Southeastern Australia. Int. J. Parasitol.. 28: 263-273.

Hughes, G. M. (1966). The Dimensions Of Gills In Relation To Their Function. J. Expt. Biol., 45: 177-195.

Hughes, G. M. (1984). General Anatomy of The Gills. In Fish Physiology X (A): 1-72. Hoar, W. S. And Randall, D. I. (Eds). London: Academic Press.

Hughes, G. M. and Morgan, M. (1973). The Structure Of Fish In Relation To Their Respiratory Function. Biol. Rev., 48: 419-475.

Kearn, G. C. (1998). Parasitism and The Platyhelminthes. Chapman And Hall Corporation. 
Khidr, A. A. (1990). Population Dynamics of Enterogyrus Cichlidurum (Monogenea: Ancyrocephalinae) From The Stomach Of Tilapia Spp. In Egypt. Int. J. Parasitol., 20(6): $741-745$.

Koskivaara. M. : Valtonen. E. T. and Vuori. K. M. (1992). Microhabitat Distribution And Coexistence of Dactylogyrus: Species (Monogenea) On Gills Of Roach. Parasitology. 1114: 273-281.

Llewellyn, J. (1956). The Host-Specificity, Micro-Ecology And Comparative Morphology of Some Trematode Gill Parasites. J. Mar. Biol. Ass. U. K. 35: 113-127.

Lo, C. M. and Morand. S. (2000). Spatial Distribution And Coexistence Of Mono'genean Gill Parasites Inhabiting Two Damselfishes From Moorea Island In French Polynesia. I. Helminthol.. $74:$ 329-336.

Lo, C. ; Morand, S. and Galzin, R. (1998). Parasite Diversity. Host Age And Size Relationships In Three Coral Reef Fishes From French Polynesia. Int. J. Parasitol., 28: 1695-1708.

Lyndon, A. R. and Vidal-Martinez. V. M. (1994). The Microhabitat And Morphology of Grubea Cochlear On The Gills Of Mackerel From Lyme Bay, Southern England. I. Mar. Biol. Ass. U. K., 7f: $731-734$.

Lyons, K. M. (1969). Sense Organs Of Monogenean Skin Parasites Ending In A Typical Cilium. Parasitology, 59: 611-623.

Ojha, J. and Hughes, M. (2001). Effect Of Branchial Parasites On The Efficiency Of The Gills of A Freshwater Catfish. Wallago Attu. J. Zool. Lond., 255: 125-129.

Paperna, I. (1964). Competitive Exclusion Of Dactylogyrus Ex/ensus By Dactylogyrus Vasicator. (Trematoda, Monogenea) On The Gills Of Reared Carp. J. Parasitol., 50: 94-98. 
Poulin, R. ; Curtis, M. A. and Rau, M. E. (1990). Responses Of The Fish Ectoparasite, Salmincola Edwardsii (Copepoda) To Stimulation, And Their Implication For Host Finding. Parasitology, 100: 417-422.

Proctor, J. (1999). What Makes A Specialist Special? Tree, 14: 333335.

Rohde, K. (1977). Habitat Partitioning In Monogeneal Of Marine Fishes. Z. Parasitenkd.. 53: 171-182.

Rohde, K. (1980). Comparative Studies On Microhabitat Utilization By Ectoparasites Of Some Marine Fishes From The North Sea And Papua New Guinea. Zoologischer Anzeiger. 204: $27-63$.

Rohde, K. (1993). Ecology Of Marine Parasites. 2nd Edition. Cab International, Oxford. $300 \mathrm{Pp}$.

Shotter, R. A. (1973). Change In The Parasite Fauna Of Whiting Odontogadus Merlangus: L. With Age And Sex Of Host. Season, And From Different Areas In The Vicinity Of The Isle Of Man. J. Fish Biol.. 5: 559-573.

Srivastava. L. P. and James. B. L. (1967). The Morphology And Occurrence Of Gyrodactylus Thedius Kathariner. 1894 (Monogenoidea) From Onosmusielus (L.). J. Nat. Hist.. J: 481-489.

Sukhdeo, M. V. K. and Sukhdeo. S. C. (1994). Optimal Habitat Selection By Helminthes Within The Host Environment. Parasitology, 109: S41-S55.

Suydam, E. L. (1971). The Micro-Ecology of Three Species Of Monogenetic Trematodes Of Fishes From The BeaufordCape Hattereas Area. Proc. Helminthol. Soc. Wash., 38: 240-246. 
Wootten, E. (1974). The Spatial Distribution Of Dactylogyris.s Amphibothrium On The Gills Of Ruffe Gymnocephalus Cernua And Its Relation To The Relative Amounts Of Water Passing Over The Parts Of The Gills. J. Helminthol. 48: 167-174.

Yuan. W. and Lang. S. (1995). Ultrastructure Of The Body Wall Of Some Monogneans. Acta Zool. Sin.. $1 /$ (2): 113-124.

Zelmer, D. A. and Arai. H. P. (1998). The Contribution Of Host Age And Size To The Aggregated Distribution Of Parasites In Yellow Perch, Perca Flavescens In Ciarner Lake. Alberta. J. Parasitol. Sin., 84: 24-28. 


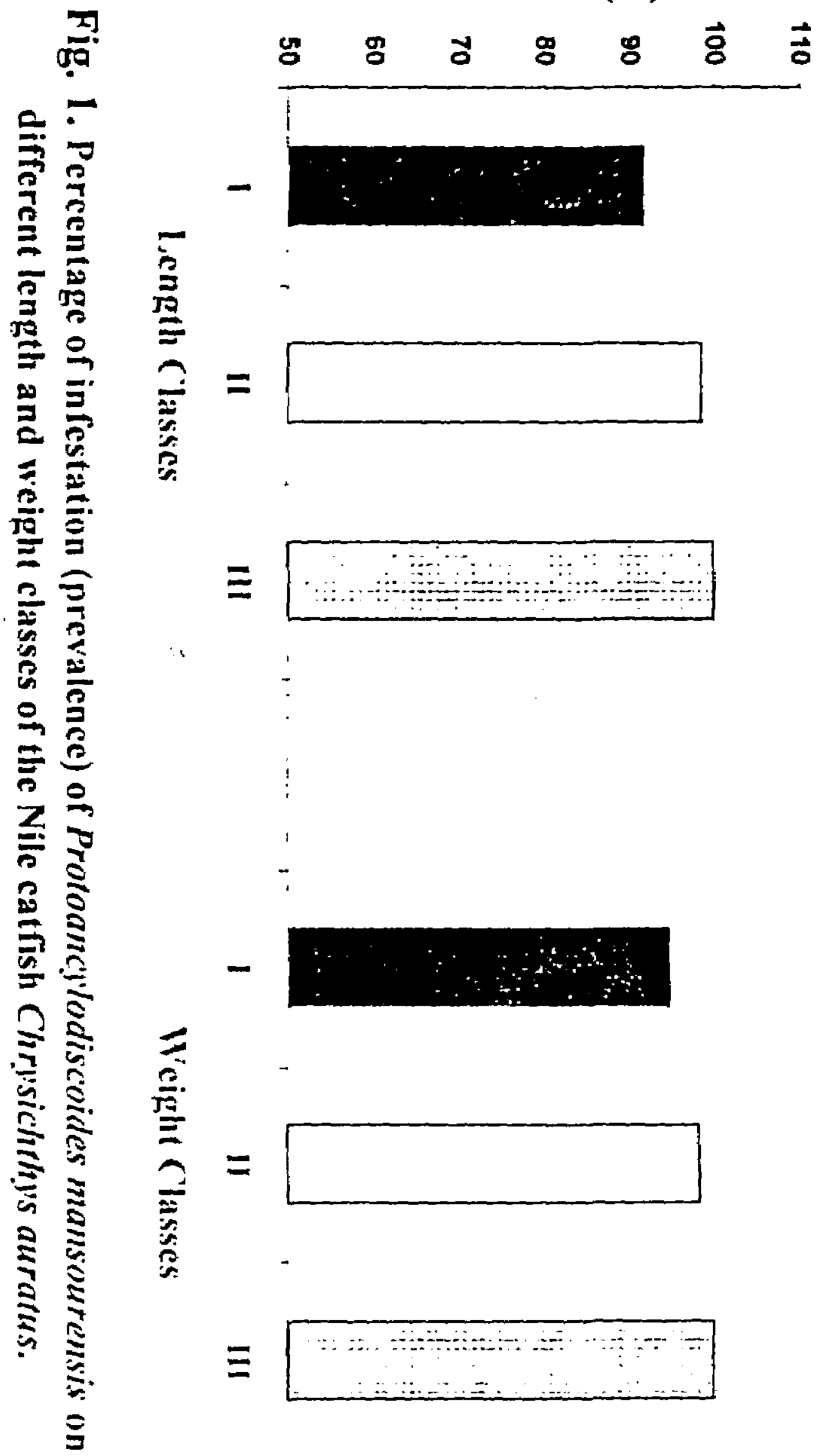




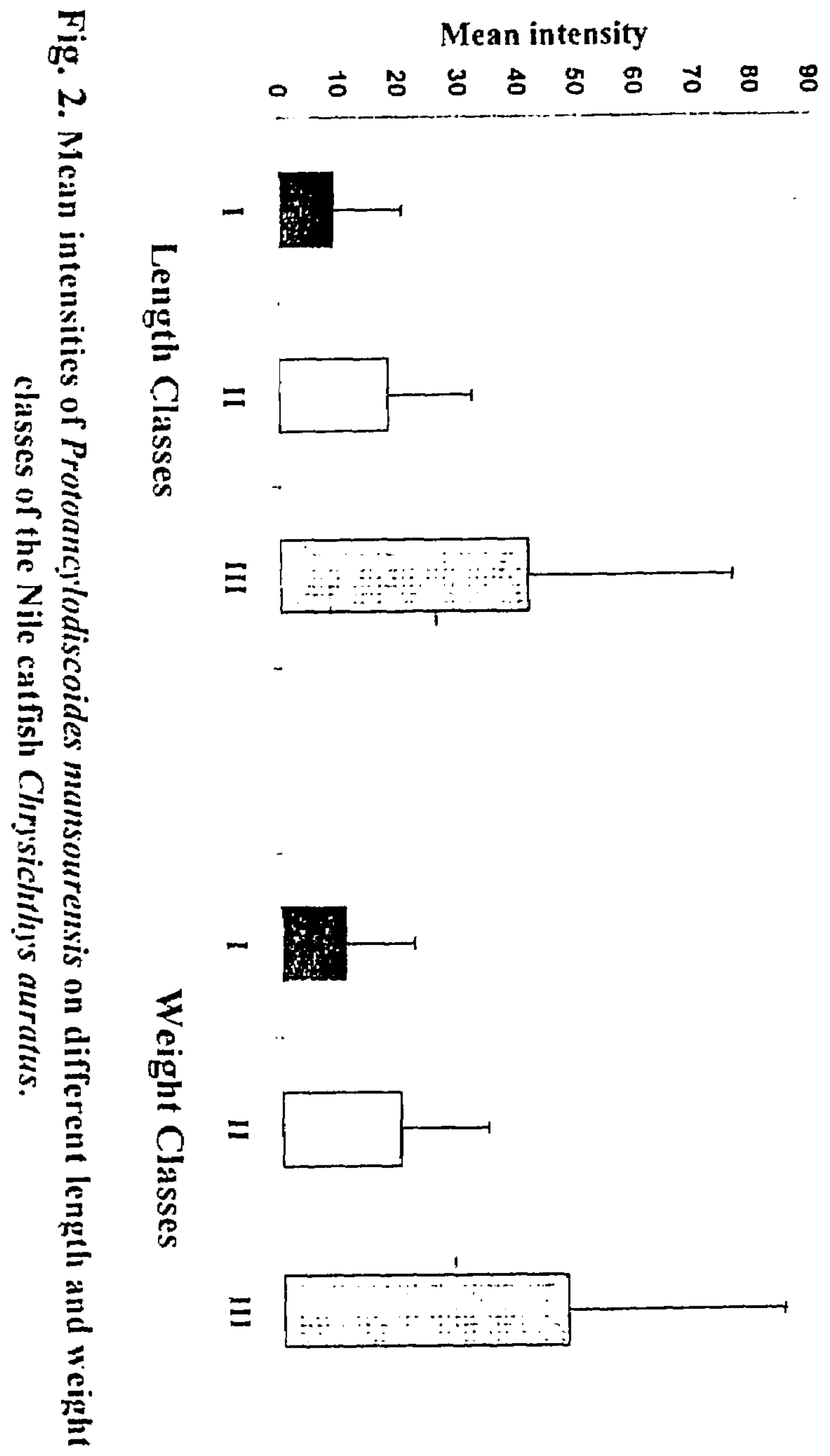




\section{LEGEND OF FIGURES}

Fig. 3. Scanning electron micrograph showing one row of the gill lamellae (gl) arranged on a single gill filament (gf) of Chrysichihys auratus. Note that adjacent gill lamellae are separated by interlamellar spaces (is). Scale bar $=100 \mu \mathrm{m}$.

Fig. 4. Scanning electron micrograph showing surface features of the gill filament (lamellae-free area) of $C$. aurarus. Note the presence of random microridges (arrowhead points) decorating pavement cells ( $p v$ ). intercellular adhesion zones (az). mucous cells $(m c)$ and microvillous chloride cells $(m v c)$. Scale bar $=5$ $\mu \mathrm{m}$.

Fig. 5. Magnified scanning electron micrograph showing relatively whorled microridges (arrowhead points) on an individual pavement cell on a gill filament of $C^{\prime}$. allratus. Note the presence of surface chloride cell (cc) neighbouring to the pavement cell and intercellular adhesion zones (az) between adjacent pavement cells (pv). Scale bar $=5 \mu \mathrm{m}$.

Fig. 6. Magnified scanning electron micrograph showing random microridges (arrowhead points) of a few pavement celis (pv). Note the presence of surface chloride cell (cc) neighbouring to the pavement cells. Note also the presence of opening of mucus cells (mc) between adjacent pavement cells. Scale bar $=5 \mu \mathrm{m}$.

Fig. 7. Scanning electron micrograph showing a typical settlement of the monogenean Protoancylodiscoides mansourensis in the interlamellar space (is) between two adjacent gill lamellae (gl) of $C$. auranis. Note that the marked widening of the affected interlamellar space. bp. Body proper of the parasite: gf. gill filament; $h$, haptor. Scale bar $=100 \mu \mathrm{m}$.

Fig. 8. Magnified scanning electron micrograph showing the haptoral attachment of $P$. mansourensis between two adjacent gill lamellae (gl) of $C$. conrotus. Note that marginal hooklets ( $\mathrm{mh} I$ and $\mathrm{mh}$ VII) do not participate in attachment. Scale bar $=20$ $\mu \mathrm{m}$.

Fig. 9. Scanning electron micrograph showing some surface features of the tegument of Protoancylodiscoides mansourensis. Note that the tegument is rich in single ciliary structures (c) and pores (arrowhead points). Each cilium emerges from the outermost layer of the tegument via a circular opening (o). Scale bar $=3 \mu \mathrm{m}$. 


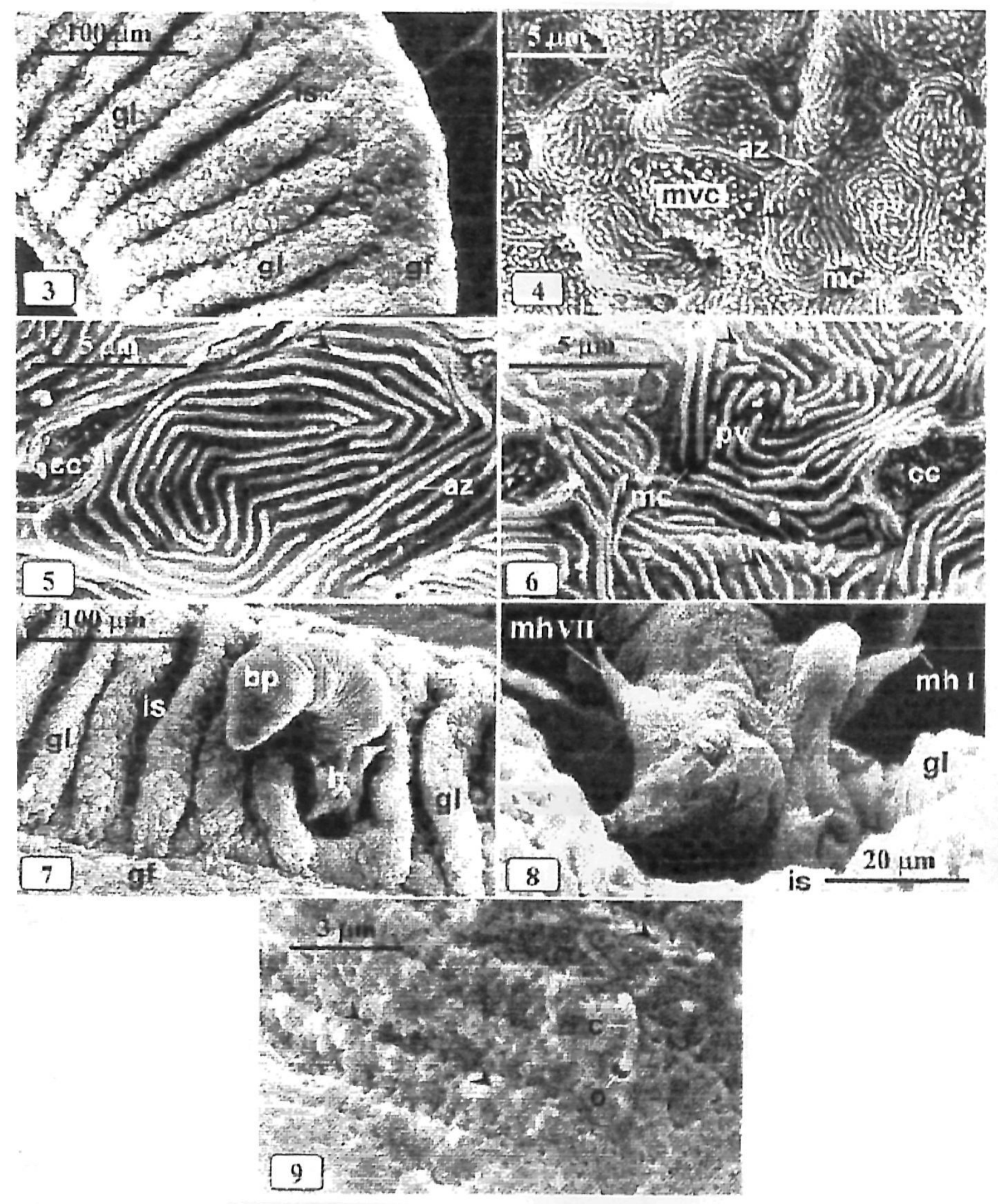




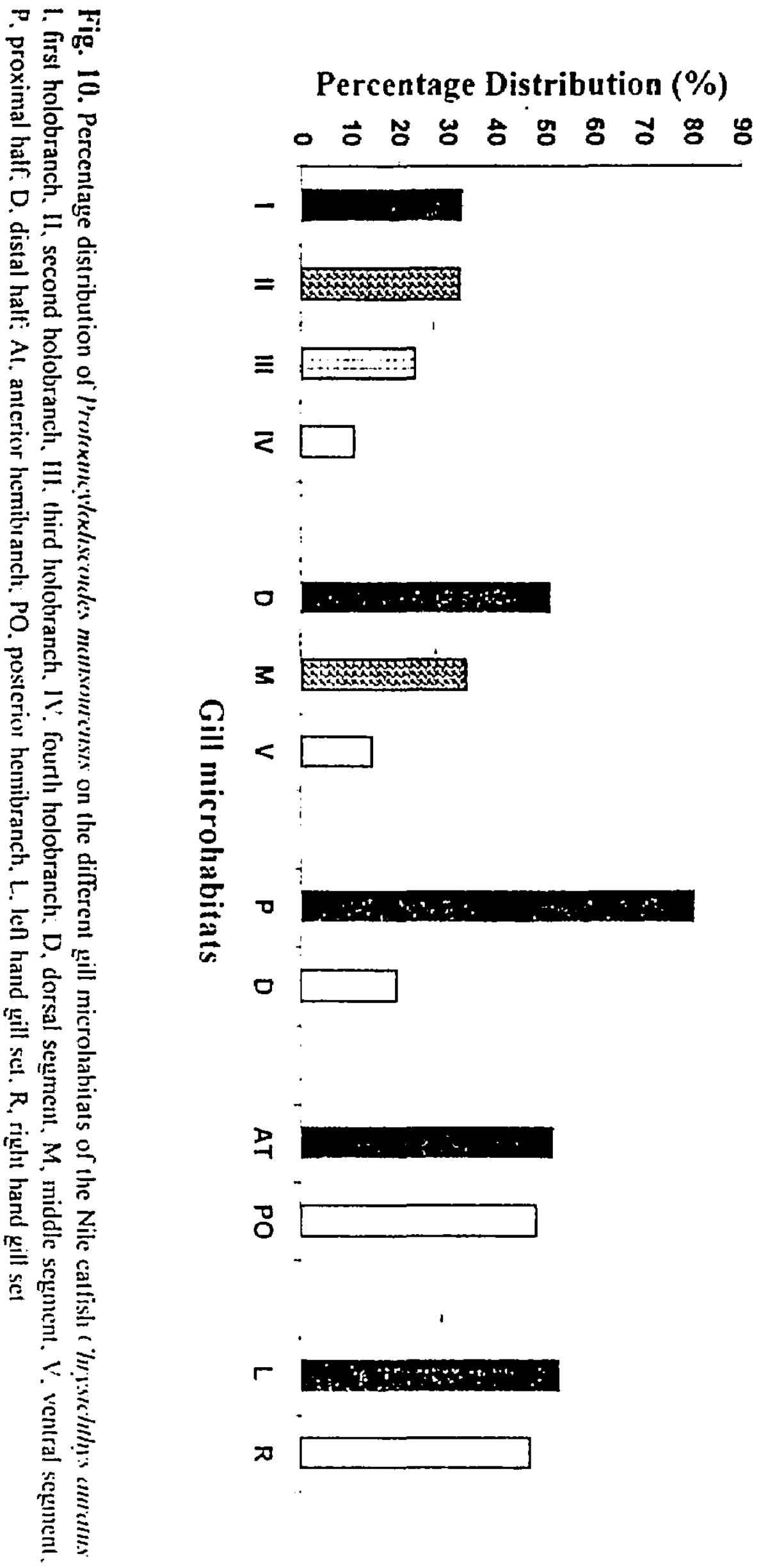

